\title{
Chapter 12 \\ GB Grid 9 August 2019 Power Outage and Grid Inertia
}

\author{
Christian Cooke
}

\begin{abstract}
A power outage on 9 August 2019 raised questions about the ability of the GB electricity grid to withstand rapid changes in frequency caused by outages and surges on the network. Grid inertia has been changing in recent years due to the emergence of renewable energy generation as a significant contributor to the energy mix. Measures to mitigate this change need to be evaluated and the level of investment required to prevent a reoccurrence of such an event quantified. An outline is presented of a research programme towards this goal.
\end{abstract}

Keywords Power system dynamics $\cdot$ Inertial response $\cdot$ Frequency control

\subsection{Introduction}

\subsubsection{An "Incredibly Rare Event" with "Immense Disruption"'[1]}

Lightning struck an overhead power line between Eaton Socon and Wymondley at 16:52.33 on Friday August 9, 2019.[2] Two major generation units went offline almost immediately (Fig. 12.1), followed by a cascade of outages that led to a cumulative power loss of 1,900 MW. This exceeded the capacity of the reserves held to maintain the integrity of supply. As a result, the power frequency, normally c. $50 \mathrm{~Hz}$, dropped to $48.8 \mathrm{~Hz}$ (Fig. 12.2), triggering exceptional measures intended to preserve the stability of the overall network. $1.15 \mathrm{~m}$ households were disconnected, thousands of commuters were turned away from train stations, while hospitals and airports also suffered disruptions. It took $5 \mathrm{~min}$ for the frequency to recover to normal levels, and $45 \mathrm{~min}$ for all connections to be restored.

The event called into question the ability of the GB national grid to withstand rapid changes in frequency caused by outages and surges on the network. This inertia has been changing in recent years due to the emergence of renewable energy generation

C. Cooke $(\varangle)$

School of Mathematics and Statistics, The Open University, Milton Keynes, UK

e-mail: christian.cooke@open.ac.uk 


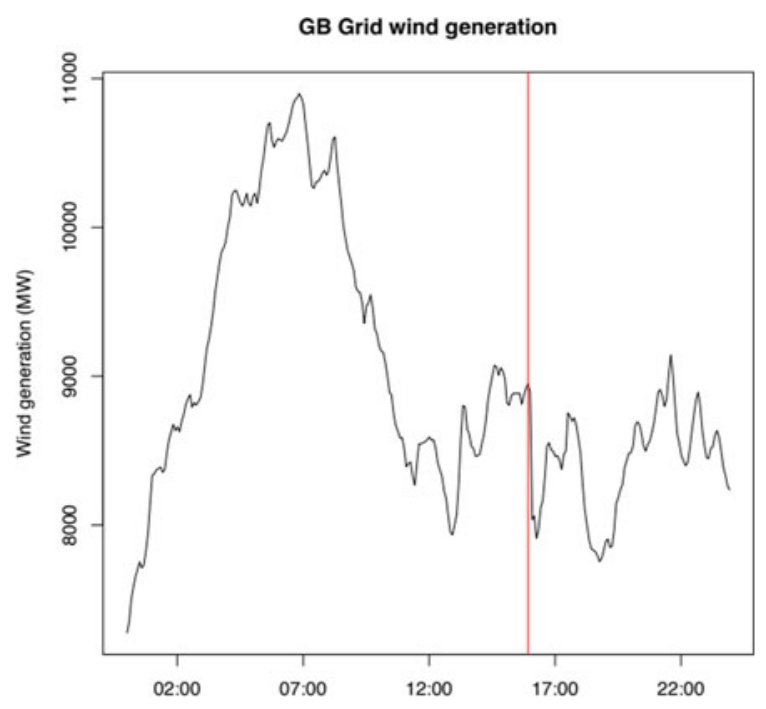

Fig. 12.1 Wind generation on August 9 2019, showing the drop in output of 737 MW from the Hornsea Windfarm (Data source: ElexonPortal.co.uk)
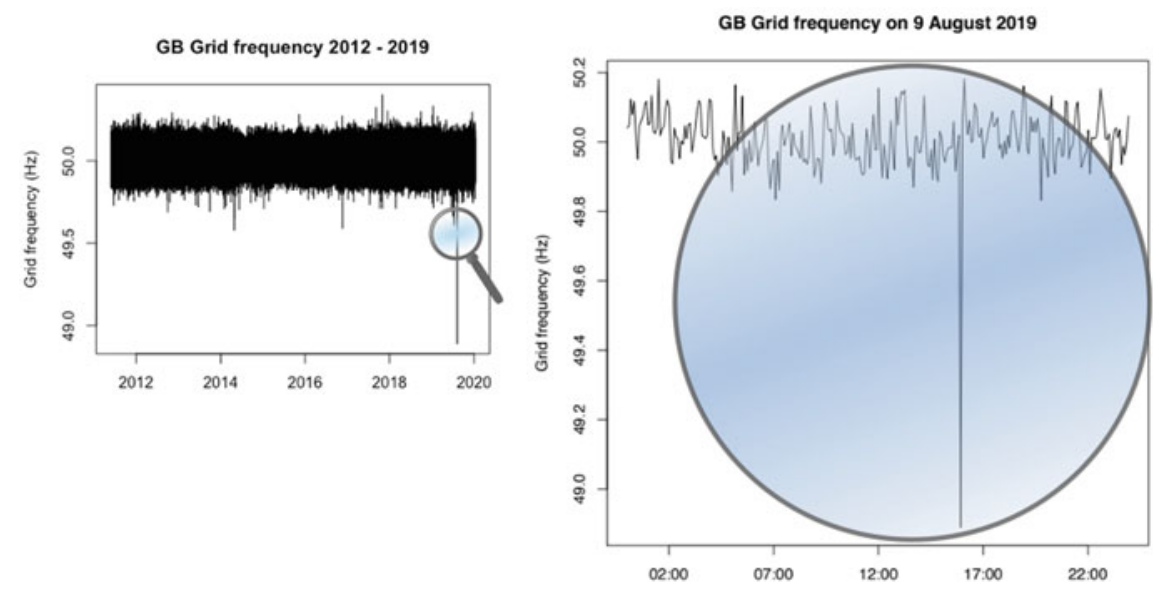

Fig. 12.2 Historical grid frequency, 2012-2019, August 92019 (Data source: https://gridwatch. templar.co.uk)

as a significant contributor to the energy mix. These power sources add to the power capacity of the network but not so much to inertia. A report into the event by Ofgem, [3] the energy regulator, recommended that the resilience of the grid should be examined in the context of this evolution of system inertia. Cost-effective measures to mitigate this change would need to be evaluated, quantifying the level of investment required to prevent a reoccurrence of an event such as the $9 / 8$ outage. 


\subsubsection{Current Trends in Power Distribution}

The increasing dependence on renewable energy to meet demand (Fig. 12.3) has been matched by the reduction in the number of fossil fuel-powered plants. Solidfuel generation invariably involves the production of steam to drive a turbine, whose mechanical energy is converted into electrical energy. These turbines have significant inherent rotational inertia. Cumulative inertia across all turbines connected to the grid is synchronous and only small deviations from the overall rate are registered by individual turbines. Industrial motors directly connected to the grid similarly contribute to the system inertia (making up a significant proportion of demand-side inertia, which is responsible for up to $20 \%$ of the total in the case of the GB grid [4]). Solar and variable-speed wind power generation involves the generation of electricity directly and therefore make no contribution to the aggregate synchronous inertia.

A sudden drop in the aggregate power causes additional power to be drawn from connected power plants to make up the deficit, manifesting as an increased load, causing the turbine rotation to slow. The turbine inertia resists this change, with the rotational energy being converted to electrical energy compensating for the shortfall and the frequency of the AC power reduces. A similar situation occurs when there is a surplus of energy on the transmission network. As a result, power outages and surges in networks where there is a reduced level of system inertia carry the risk of rapid frequency changes. Frequency changes beyond permissible levels cause permanent damage and malfunction in AC motors connected to this supply.

It is clear that in the context of reduced systemic synchronous inertia, the consequences for grid management of the current and projected evolution of the power generation portfolio must be examined. Alternatives to alleviate the shortfall are the subject of active research: synchronous compensators, battery energy storage systems (BESS), synthetic inertia from wind turbines, and demand-side management. More accurate measurement of system inertia would also allow a more sophisticated response to network demands for inertia compensation.
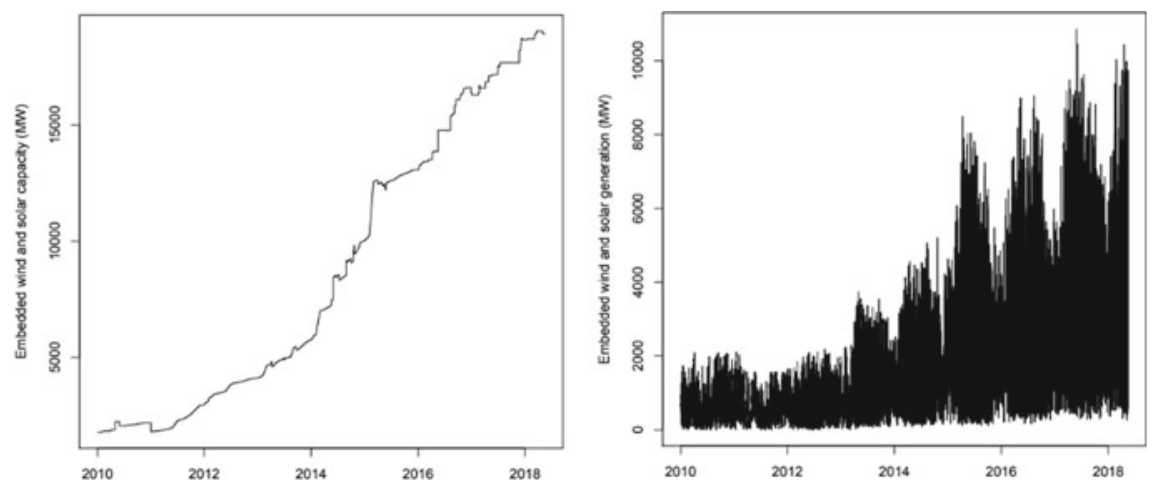

Fig. 12.3 GB grid renewable energy capacity and generation 2010-2018 (Data source: https://gri dwatch.templar.co.uk) 


\subsection{Investigations}

\subsubsection{Objectives}

The focus of the project being undertaken is to design a model that permits an examination of the issues raised by the evolution of the energy mix on the national and international grid. To do this effectively the sophistication of the model must be balanced with its simplicity.

To fulfil these objectives the model should achieve a realistic overview of the impact of the evolution in generation mix, and consequent inertia profile, on grid stability. It should have the robustness necessary to identify situations leading to events such as that of August 9 and the flexibility to admit radical variations in energy mix under a variety of possible future scenarios.

An approach firmly rooted in nonlinear dynamical systems and control theory is intended, offering a continuous-time differential-equation model of the whole grid. To achieve this, an initial "toy" model is planned, using aggregated data grouped by the type of energy source, renewable (wind, solar), baseline (nuclear) and fossil fuel (gas, coal). The model is based on the stylized DC-Flow paradigm.

\subsubsection{Initial Design to Study 9 August Outage}

Demand is obtained from the 5-min Balancing Mechanism reporting, and this value is assigned to the single load bus. The frequency data used is the $1 \mathrm{~s}$ National Grid frequency database. Further refinement of the output would be obtained from a higher resolution data source which could be supplemented into the model without alteration.

Into this network we simulate the instantaneous frequency response by adjusting the output variables by levels corresponding to the recorded losses. The frequency $f$ is obtained using the well-known swing bus equation [5], augmented with noise $\eta$ driven by an Ornstein-Uhlenbeck process. In standard stochastic differential equation notation, the equations are.

$$
d f=\left(-\lambda_{1} \Delta f-\lambda_{2} \Delta P+\eta\right) d t, \quad d \eta=-\eta / \tau d t+\sigma d W
$$

where $\Delta f$ is the deviation of the frequency from $50 \mathrm{~Hz}, \Delta P$ is the mismatch between the generated power and the load, and $W$ is standard Brownian motion. The parameters $\lambda_{1}$ and $\lambda_{2}$ have been calibrated to match the recorded frequency trace of the event. $\Delta P$ is determined based on the timeline of losses and frequency responses detailed in the ESO and Ofgem reports on the incident [2, 3]. The noise parameters $\tau$ and $\sigma$ have been chosen to match approximately the variations in the measured frequency trace. 


\subsection{Results and Discussion}

The result of the simulation (Fig. 12.4) shows a correspondence between the frequency trace of the $9 / 8$ event and the model. The model describes well the initial drop in frequency and its recovery, although it does not capture the subsequent overshoot in frequency after the losses are corrected.

We can use this correspondence to evaluate the effectiveness of the frequency response services deployed during the event, showing that the Control Room measures were more effective than LFDD (Low Frequency Demand Disconnection, where $1.15 \mathrm{~m}$ customers were put offline). Figure 12.5(i) shows that the simulated frequency trace returns close to $50 \mathrm{~Hz}$ without the LFDD intervention, whereas Fig. 12.5(ii) shows that without the Control Room actions the frequency falls further and remains below critical levels.

We can furthermore evaluate future frequency response technologies. The specification of the Dynamic Containment service to be launched by the ESO in Autumn 2020 [6] indicates that, to prevent a frequency drop of $1.2 \mathrm{~Hz}$ from an immediate

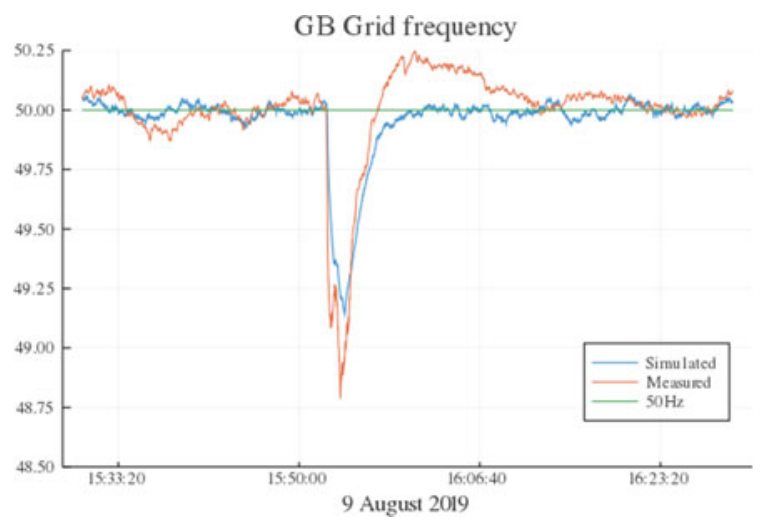

Fig. 12.4 Measured and simulated GB Grid
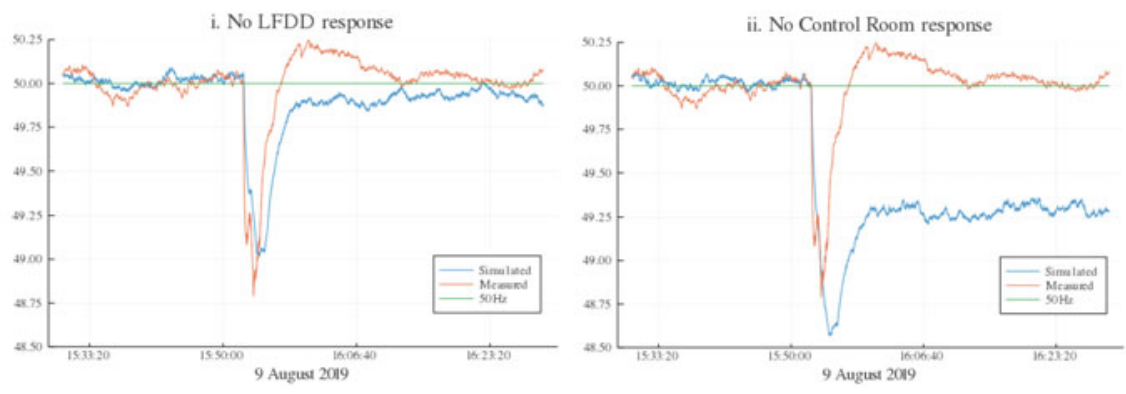

Fig. 12.5 August 9th simulation excluding LFDD (i) and Control Room (ii) responses 
Fig. 12.6 Estimated frequency nadir for ESO Dynamic Containment frequency response
Grid frequency minimum $-1.541 \mathrm{GW}$ loss

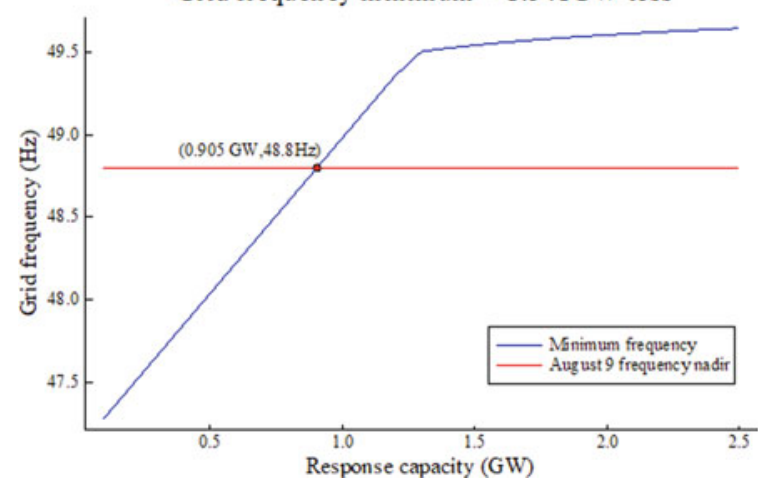

loss of $1.541 \mathrm{GW}$, equivalent to that at the outset of the $9 / 8$ event, a capacity greater than 905 MW would be needed (Fig. 12.6).

The model can be improved by assigning sources of frequency response (battery, pumped hydroelectric, synchronous compensators) to individual variables so as to facilitate their calibration, thereby assessing their contribution to mitigating the effects of significant losses of the $9 / 8$ outage. The inertia of the system $H_{s y s}$ may be obtained from the inertial constants of the generation sources.

$$
H_{s y s}=\frac{\sum_{i=1}^{N} S_{i} H_{i}}{S_{t o t}}
$$

$S_{\text {tot }}=\sum_{i=1}^{N} S_{i}$ is the sum of the rated powers of the $N$ generators and $H_{i}$ is the $i$ th generator's inertia coefficient. The simulated frequency is obtained by integrating an aggregate model of the form given in the following coupled differential equations:

$$
\frac{d G}{d t}=F_{G}(D, O, G, f) \quad \frac{d f}{d t}=F_{f}(D, O, G, f)
$$

where $G$ and $f$ are the simulated aggregated conventional generated and system frequency, $D$ is the aggregate demand, $O$ is system output comprising generation and renewables, and the functions $F_{G}, F_{f}$ couple $G$ and $f$ through the system mismatch $D-O$.

\subsection{Conclusion}

Changing grid inertia is already a significant issue for grid operators and regulators. The trend for reduced mechanical inertia from traditional sources will accelerate, as renewables and interconnection form an increasing part of the energy mix. Measures 
will need to be put in place to replace current sources of inertia in order to avoid the proliferation of further events comparable to the $9 / 8$ incident in future. To further this goal, models will be needed that simulate rapid changes in frequency, the effects of grid inertia, and the effectiveness of proposed measures to mitigate adverse outcomes. These models will require a sophistication sufficient to provide a realistic evaluation of current and possible scenarios, and be adequately schematic so as not to require unnecessarily intense computational resources.

\section{References}

1. BBC News, UK power cut: National Grid promises to learn lessons from blackout (2019). $10 / 8 / 2019$

2. ESO, Technical Report on the events of 9 August 2019 (2019). 6/9/2019

3. Ofgem, 9 August 2019 power outage report (2020). 3/1/2020

4. Y. Bian, H. Wyman-Pain, F. Li, R. Bhakar, S. Mishra, N.P. Padhy, Demand Side Contributions for System Inertia in the GB Power System. IEEE Trans. Power Syst. 33(4), 3521-3530 (2018)

5. P. Vorobev, D.M. Greenwood, J.H. Bell, J.W. Bialek, P.C. Taylor, K. Turitsyn, Deadbands, Droop, and Inertia Impact on Power System Frequency Distribution. IEEE Trans. Power Syst. 34(4), 3098-3108 (2019)

6. ES, Dynamic containment (2020). Retrieved from https://www.nationalgrideso.com/industryinformation/balancing-services/frequency-response-services/dynamic-containment

Open Access This chapter is licensed under the terms of the Creative Commons Attribution 4.0 International License (http://creativecommons.org/licenses/by/4.0/), which permits use, sharing, adaptation, distribution and reproduction in any medium or format, as long as you give appropriate credit to the original author(s) and the source, provide a link to the Creative Commons license and indicate if changes were made.

The images or other third party material in this chapter are included in the chapter's Creative Commons license, unless indicated otherwise in a credit line to the material. If material is not included in the chapter's Creative Commons license and your intended use is not permitted by statutory regulation or exceeds the permitted use, you will need to obtain permission directly from the copyright holder.

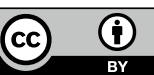

